\title{
A New Species, Lamispina ammophila sp. nov. (Annelida: Flabelligeridae), from Shimoda, Japan
}

\author{
Naoto Jimi ${ }^{1,2}$ and Hiroshi Kajihara ${ }^{1}$ \\ ${ }^{1}$ Department of Natural History Sciences, Graduate School of Science, Hokkaido University, \\ Kita 10 Nishi 8 Kitaku, Sapporo, Hokkaido 060-0810, Japan \\ E-mail: beniimo7010@gmail.com \\ ${ }^{2}$ Corresponding author
}

(Received 3 November 2017; Accepted 28 February 2018)

http://zoobank.org/8C1D3C7A-15A5-4DF1-86FB-4D5C1252B9FF

\begin{abstract}
A new species of flabelligerid polychaete, Lamispina ammophila sp. nov., is described from off the coast of Shimoda, Japan. The species can be discriminated from the other congeners by the following features: $i$ ) dorsal region of body being adhered to by sediment particles, ii) lamispines without accessory tooth, present from chaetiger 4 and succeeding chaetigers, and iii) cephalic cage 1.5-2.0 times as long as body width. A partial mitochondrial cytochrome $c$ oxidase subunit I (COI) gene sequence from the paratype is provided as a DNA barcode for the new species.
\end{abstract}

Key Words: Marine invertebrates, new species, Polychaeta, polychaetes, taxonomy.

\section{Introduction}

Lamispina Salazar-Vallejo, 2014 is one of the 25 genera in the polychaete family Flabelligeridae, consisting of nine species reported from intertidal to deep sea sediment in subtropical to cold-temperature waters (Salazar-Vallejo 2014). The genus was proposed so that it accommodates species formerly placed in Pherusa Oken, 1807 having special neurochaetae (Grube 1877; Haswell 1892; Annenkova-Chlopina 1924; Støp-Bowitz 1948; Hartmann-Schröder 1965; SalazarVallejo 2014). Members in Lamispina possess special neurochaetae, called "lamispines", in which their distal area is thin and broad. This is one of the main features that distinguishes them from other flabelligerids.

Around Japan, a sole species of the genus, L. schmidtii (Annenkova-Chlopina, 1924), has been known from the Japan Sea and Okhotsk Sea (Annenkova-Chlopina 1924; Salazar-Vallejo 2014). During the 8th Japanese Association for Marine Biology (JAMBIO) Coastal Organism Joint Survey held at Shimoda, the first author found some specimens of Lamispina. We describe the specimens as a new species and provide COI sequences as a DNA barcode of the species.

\section{Materials and Methods}

Fresh specimens were collected by dredging from off the coast of Shimoda, Japan $\left(34^{\circ} 39.217^{\prime} \mathrm{N}, 138^{\circ} 57.106^{\prime} \mathrm{E}\right.$ to $\left.34^{\circ} 39.071^{\prime} \mathrm{N}, 138^{\circ} 56.977^{\prime} \mathrm{E}\right)$. The specimens were fixed in $70 \%$ ethanol. After preservation, these specimens were observed with a Nikon SMZ1500 dissecting microscope and an OLYMPUS BX51 compound light microscope, and then photographed with a Nikon D5200 digital camera. All the material has been deposited in the National Museum of Nature and Science, Tsukuba (NSMT).

DNA extraction and sequencing of part of the COI were carried out following the method of Jimi and Fujiwara (2016). The newly obtained sequence has been deposited in the DNA Data Bank of Japan.

\section{Systematics}

Genus Lamispina Salazar-Vallejo, 2014

[New Japanese name: sasanoha-habouki-zoku] Lamispina ammophila sp. nov.

[New Japanese name: suna-sasanoha-habouki]

(Figs 1, 2)

Material examined. Holotype: NMST-Pol H-663, anterior fragment, $4 \mathrm{~mm}$ long, $1 \mathrm{~mm}$ wide (widest chaetiger), 17 chaetigers, sex unknown, off Shimoda, 45-46 m depth, 13 November 2015, collected by NJ; although the last two chaetigers were removed for observation and DNA extraction, any gene sequences could not be determined from those chaetigers. Paratypes: NSMT-Pol P-664, 10 specimens, anterior fragments, 2-6 $\mathrm{mm}$ long, $1 \mathrm{~mm}$ wide (widest chaetiger), 8-20 chaetigers, sex unknown, off Shimoda, 45-46m depth, 13 November 2015, collected by NJ; the last two chaetigers and palps of one specimen were removed for DNA extraction.

Sequence. LC363891, COI gene, $651 \mathrm{bp}$, determined from the paratype (NSMT-Pol P-664).

Description. Holotype $4 \mathrm{~mm}$ long, $1 \mathrm{~mm}$ wide (widest chaetiger), 17 chaetigers (not complete). Body cylindrical, tapered in posterior region, greenish in life, yellowish after 


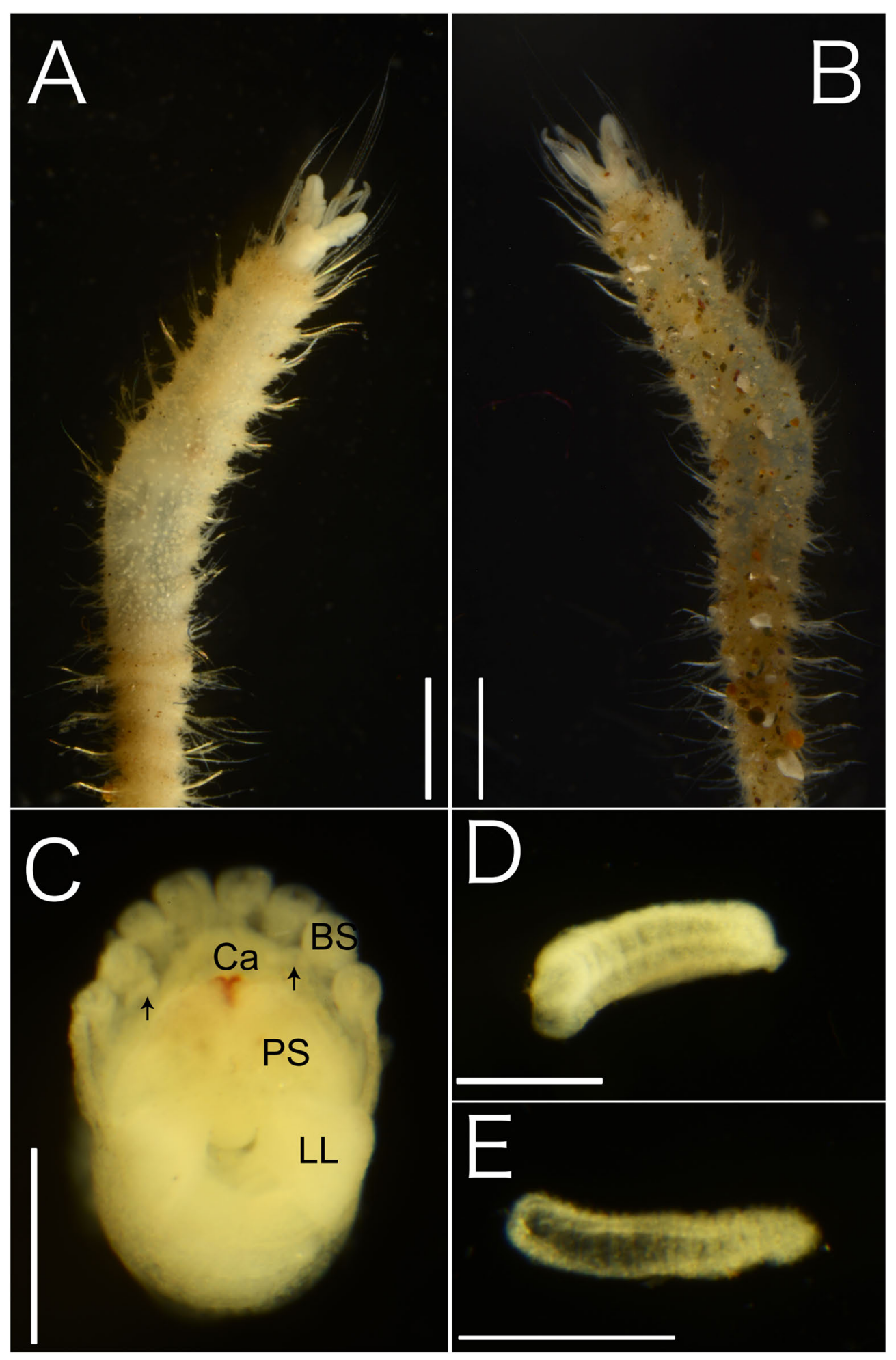

Fig. 1. Photographs of Lamispina ammophila sp. nov. in preserved state. A, B, D, E, Holotype, NSMT-Pol H-663; C, paratype, NSMT-Pol P-664. A, Anterior end, ventral view; B, anterior end, dorsal view; C, prostomium (BS, branchial scar; Ca, caruncle; LL, lateral lip; PS, palp scar; black arrows, nephridial lobe); D, palp; E, branchia. Scale bars: A-B, $1 \mathrm{~mm}$; C-E, $250 \mu \mathrm{m}$.

fixation (Fig. 1A). Dorsal body surface with sparse sand particles (Fig. 1B), ventral side without sand particles (Fig. 1A). Body papillae long, thin, digitate, sediment particles attached on base, 1/2 times as long as parapodial papillae. Gonopodial lobes not seen. Gonopores not seen.

Prostomium low cone, red eyes present, caruncle devel- oped, lateral lip expanded, dorsal and ventral lips not well developed (Fig. 1C). Palps short, thick, digitate, as long as branchiae (Fig. 1D). Branchiae arranged in a continuous dorsal series, eight in number, digitate, microcilia present on surface (Fig. 1E). Nephridial lobes present.

Cephalic cage well developed, 1.5-2.0 times as long as 


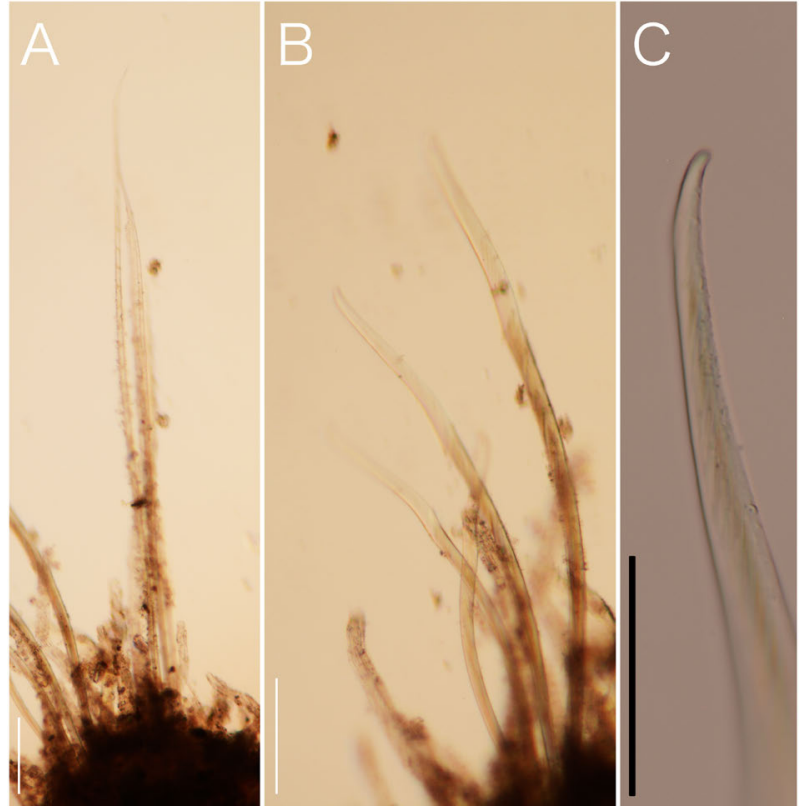

Fig. 2. Photomicrographs of chaetae (chaetiger 17) in Lamispina ammophila sp. nov., holotype, NSMT-Pol H-663. A, Notochaetae; B, neurochaetae; C, tip of neurochaeta. Scale bars: A, B, $100 \mu \mathrm{m}$; C, $50 \mu \mathrm{m}$.

body width (widest chaetiger). Chaetigers 1-3 comprise cephalic cage, cephalic cage consisting of about 4 notochaetae and 8 neurochaetae (some chaetae broken). Chaetal transition from cephalic cage to body chaetae abrupt (Fig. 1A).

Parapodia poorly developed. Noto- and neuropodial low lobes, 1/3-3/4 times as long as neurochaetae, 2-4 times as long as body papillae, 5-7 internal papillae, 4-6 postchaetal papillae; 4-5 chaetae per notopodia, 3-4 chaetae per neuropodia. Notochaetae multiarticulated capillaries, brownish, with articles medium-sized basally, long medially and distally (Fig. 2A). Neurochaetae multiarticulated capillaries in chaetigers 1-3, brownish; anchylosed lamispines present in chaetiger 4 and succeeding posterior chaetigers, brownish, without accessory tooth, with articles medium-sized basally, slightly long medially (Fig. 2B, C).

Posterior end unknown.

Etymology. The specific name "ammophila" derives

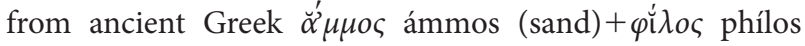
(loving, friendly), referring to the new species having sand particles on its body.

Distribution. Only known from the type locality, Shimoda, Japan. 45-46 $\mathrm{m}$ in depth.

Remarks. Lamispina ammophila sp. nov. is different from the other known species by the following features: $i$ ) sediment particles are adhered only to the dorsal region of the body, ii) lamispines are present in chaetiger 4 and backward, lacking accessory tooth, and iii) the cephalic cage is 1.5-2.0 times as long as the body width. The species resembles L. amoureuxi Salazar-Vallejo, 2014 in having sediment particles and lamispines without accessory tooth. While lamispines in L. ammophila sp. nov. emerge from chaetiger 4 and backward, they occur from chaetiger 2 in L. amoureuxi.
The cephalic cage is 1.5-2.0 times as long as body width in L. ammophila sp. nov., it is as long as body in L. amoureuxi. The species also resembles L. gymnopapillata (HartmannSchröder, 1965) in that lamispines occur from chaetiger 4, but it differs from the latter in that sand particles adhere dorsally in L. ammophila sp. nov., whereas L. gymnopapillata does not carry sand particles.

\section{Key to Species of the Genus Lamispina [Modified from Salazar-Vallejo (2014)]}

1. Body papillae without sand or large sediment particles ............................................ 2

- Body with sand or larger particles, at least dorsally;

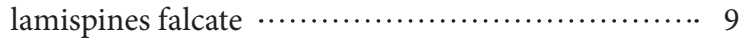

2. Body papillae stiff, tapered or conical …........... 3

- Body papillae delicate, filiform, often eroded leaving bare surfaces …............................... 7

3. Lamispines tapered, tips acuminate $\ldots \ldots \ldots \ldots \ldots \ldots . . \ldots$

- Lamispines subdistally widened, tips falcate ......... 5

4. Lamispines from chaetiger 3; notochaetae abundant (9-12 per bundle); four transverse series of papillae on medial segments

\section{L. kerguelarum (Grube, 1877): Southern Indian Ocean}

- Lamispines from chaetiger 4; notochaetae sparse (5 per bundle); two transverse series of papillae on medial segments …... chilensis Salazar-Vallejo, 2014: SE Pacific (Chile)

5. Cephalic cage $6 \times$ longer than body width; medial parapodia with 8 notochaetae per bundle ............ … L. carrerai Salazar-Vallejo, 2014: NE Pacific (Mexico)

- Cephalic cage 2-3× longer than body width ........ 6

6. Medial parapodia with 5-6 notochaetae per bundle; body with 3-5 transverse series of papillae per segment … L. horsti (Haswell, 1892): Southern Australia

- Medial parapodia with 10 notochaetae; body with 4-6 transverse series of papillae per segment ........ ...... L. gymnopapillata (Hartmann-Schröder, 1965): SE Pacific (Chile)

7. Notochaetae longer than body width ............... 8

- Notochaetae $1 / 3$ as long as body width; 7-8 lamispines per bundle, tips with fibers exposed; body with 2 transverse series of papillae per segment L. milligani Salazar-Vallejo, 2014:

NE Atlantic (Florida)

8. Medial segments with 5-7 lamispines per bundle, tips hooded, appearing bidentate; body with 5-6 transverse series of papillae per segment ............. .......... L. schmidtii (Annenkova-Chlopina, 1924): Japan Sea

- Medial segments with 4-5 lamispines per bundle, tips entire, smooth; body with 8-10 transverse series of papillae per segment

......... L. falcata (Støp-Bowitz, 1948): Norwegian Sea

9. accessory tooth in neurochaetae absent $\ldots \ldots \ldots \ldots \ldots 10$

- accessory tooth in neurochaetae present ............. 


\section{L. keeli Salazar-Vallejo, 2014: Gulf of Mexico (Florida)}

10. Lamispines from chaetiger 2; cephalic cage as long as body width...... L. amoureuxi Salazar-Vallejo, 2014:

NE Atlantic (off SW Ireland)

- Lamispines from chaetiger 4; cephalic cage 1.5-2.0 times as long as body width

L. ammophila sp. nov.: Japan

\section{Acknowledgments}

We thank Dr. Hiroaki Nakano, Mr. Yasutaka Tsuchiya, and the members of Shimoda Marine Research Center, University of Tsukuba. Messrs. Hisanori Kohtsuka and Mamoru Sekifuji and all the other participants in the 8th JAMBIO Coastal Organism Joint Survey held at Shimoda for generous help in collecting the samples. We are also grateful to Drs. Sergio I. Salazar-Vallejo, Alexandra Rizzo, Takafumi Nakano for providing informative comments; and Dr. Kevin Wakeman for correcting the English. This study was supported by JAMBIO and JSPS KAKENHI (No. JP17J05066) to NJ.

\section{References}

Annenkova-Chlopina, N. 1924. Neues über die Verbreitung einiger Arten der Polychaeten. Comptes Rendus de l'Académie des Sciences de Russie 1924: 125-128.

Grube, A. E. 1877. Anneliden - Ausbeute S.M.S. Gazelle. Monatsberichte der Königlichen Preussischen Akademie des Wissenschaften zu Berlin 1877: 507-554.

Hartmann-Schröder, G. 1965. Die Polychaeten des Sublitorals. Zur Kenntnis des Sublitorals der chilenischen Küste unter besonderer Berücksichtigung der Polychaeten und Ostracoden. (Mit Bemerkungen über den Einfluss sauerstoffarmer Strömungen auf die Besiedlung von marinen Sedimenten). Mitteilungen aus dem Hamburgischen Zoologischen Museum und Institut 62: 59-305.

Haswell, W. A. 1892. Observations on the Chloraemidae, with special reference to certain Australian forms. Proceedings of the Linnean Society of New South Wales, Series 2 6: 329-356.

Jimi, N. and Fujiwara, Y. 2016. New species of Trophoniella from Shimoda, Japan (Annelida, Flabelligeridae). ZooKeys 614: 1-13.

Salazar-Vallejo, S. I. 2014. Revision of Pherusa Oken, 1807 (Polychaeta: Flabelligeridae). Zootaxa 3886: 1-61.

Støp-Bowitz, C. 1948. Les Flabelligériens Norvégiens. Bergens Museums Årbok 1946: 1-59. 